\title{
e-interview
}

columns

\section{Til Wykes}

Til Wykes is Professor of Clinical Psychology and Rehabilitation at the Institute of Psychiatry, King's College London and a clinical psychologist at the South London and Maudsley NHS Foundation Trust. She is Director of the UK Mental Health Research Network. She trained at the Universities of Nottingham, Sussex and London. Her main interest is in developing and evaluating novel treatments to improve recovery in people with severe psychosis.

If you were not a psychologist, what would you do?

Throwing aside any ambition I had to be a ballet dancer or an astronaut, at age 13 I decided to be a psychologist. I had run out of what the village librarian deemed 'suitable' novels and so she pointed me to the non-fiction section. I selected a book on psychology and never looked back but, if I'd been taller, I could have been an accountant or an architect.

What has been the greatest impact of your profession on you personally? Being able to talk to the experts on mental health problems - mental health service users themselves. It is the most intellectually stimulating part of my work and has given me much cause to question what professionals do.

\section{Do you feel stigmatised by your profession?}

Only at parties with gullible people who think I can tell them about their dreams. This is a consistent theme in these e-interviews and so until we can educate the public perhaps we should hide behind the mantle of a health economist; after all we often feel like one.

\section{What are your interests outside of work? \\ Nothing unusual - travel, reading, films and indulging and being indulged by my family.}

Who was your most influential trainer, and why?

There are too many to list and many were not professionals at all.

What job gave you the most useful training experience?

Ward rounds with Michael Shepherd, when I wasn't in the firing line. I developed

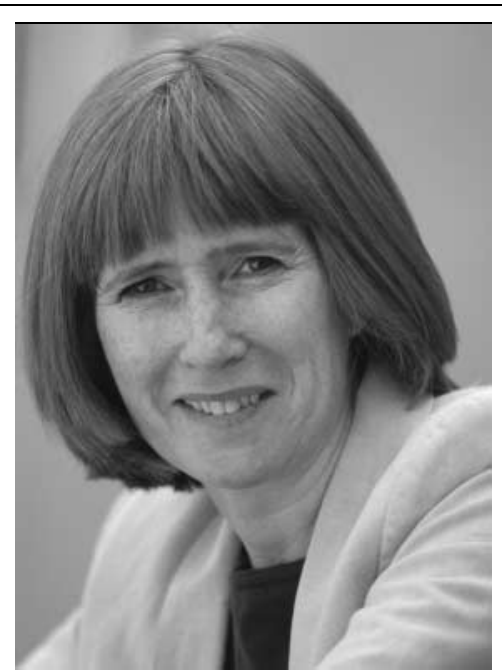

empathy with the unwitting senior house officer victims, methods of giving in gracefully and the common sense never to try to argue any case on thin evidence.

Which book has influenced you most? That first non-fiction library book whatever it was.

What research publication has had the greatest influence on your work? Interactions with researchers, in the Institute of Psychiatry canteen or the conference bar, have most influenced my work not publications.

What part of your work gives you the most satisfaction?

Working with service users and hearing their views on how to create successful, novel therapies.

\section{What do you least enjoy?}

Writing service development plans. By the time they are finally negotiated they are out of date as the National Health Service faces yet another policy change or financial pressure. At least a research publication is read by the peer reviewers, but often no one reads the service plan.

\section{What single change would} substantially improve quality of care? Not one but two - first reduce the stigma and discrimination associated with mental health problems and second reduce bureaucracy, so that talented clinicians can spend their time improving patient care.
What conflict of interest do you encounter most often? Fighting for mental health research as the Director of UK Mental Health Research Network.

Do you think psychiatry is brainless or mindless?

It has recently been mindless and had too much brain but I'm still hopeful that you (and I) will get the balance right. It is vital that we don't confuse pretty brain images with hallucinations, insight or arithmetic ability. These pictures can change if people just choose to do a task differently and the most interesting question is - 'what affects this choice?'

What is the most important advice you could offer to a new trainee? There is a lot of clinical equipoise around, so don't patronise your patients by trying to appear to know the right answers to the management of all their problems.

How would you improve clinical psychiatric training?

I wouldn't drum the scepticism out of trainees. They need to know that professional practice is about acting on what little we know now. Clinical equipoise is what drives research and research is vital to improving psychiatric practice; so everyone, in whatever profession, needs to get involved.

How should the role of the Royal College of Psychiatrists change? I have never been clear about what its role is, but for us on the outside it would be helpful if there was more dialogue with other mental health professionals in all professional arenas. It could be a powerful force for the improvement of the nation's mental health.

\section{What single area of psychiatric} research should be given priority? I am eager to discover programmes of therapy that lead to recovery in those who have the most disability, but this does not exclude many areas of research. Perhaps we do need to try to investigate some simple questions that would have immediate implications for care. Solving some of these issues should promote enthusiasm among all clinical professions and encourage all professionals to take part in the research process.

Dominic Fannon

doi: 10.1192/pb.bp.107.014712

\section{corrigendum}

Clinical attachments in psychiatry Psychiatric Bulletin, 31, 104-106. The doi for this special article is $10.1192 /$ pb.bp.106.010249; the doi included with the online version has been corrected in deviation from print and in accordance with this corrigendum. doi: $10.1192 / \mathrm{pb} .31 .4 .160$ 